International Journal of Instruction e-ISSN: 1308-1470 • www.e-iji.net

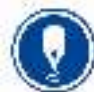

January $2021 \bullet$ Vol.14, No.1

p-ISSN: 1694-609X

pp. $907-926$

Article submission code

20200325125417

Received: $25 / 03 / 2020$

Revision: 09/08/2020

Accepted: $30 / 08 / 2020$

OnlineFirst: 05/12/2020

\title{
Effects of Infographics on Developing Computer Knowledge, Skills and Achievement Motivation among Hail University Students
}

\section{Usama M. Ibrahem}

Asst. Prof., Educational Technology, Hail University, Saudi Arabia, u.abdelsalam@uoh.edu.sa

\author{
Abdulaziz R. Alamro \\ Assoc. Prof., Curriculum and Instruction, Hail University, Saudi Arabia, \\ dr.alamr@uoh.edu.sa
}

$\mid$

The study aims to explore the difference between static infographics (SIs) and animated infographics (AIs) for developing e-learning and computer skills as well as increasing achievement motivation in students enrolled in e-learning and computer skills course in the second term of 2018/2019 at the Preparatory Year Program at the University of $\mathrm{Ha}$ 'il $(\mathrm{UoH})$. The study sample of 80 male and female students were involved into 4 experimental groups. 40 students in group 1 and 2 studied the content through SIs while the other 40 students in group 3 and 4 studied the content through AIs. The independent variables in this research consisted of SIs and AIs embedded learning content while achievement of elearning and computer skills and achievement motivation were the dependent variables being observed. Pre-tests and post-tests results showed that the learning materials positively influenced the students' computer skills, e-learning, achievement motivation. This study revealed that the use of SI had a greater effect on female student learning while AI was found more effective for male student learning. We believe that the current study might contribute particularly to the use of infographics for defining clear educational goals and curriculum reforms reflecting students' needs, ability, gender, age and the context.

Keywords: infographics, achievement motivation, e-learning, visual representation, skill

\section{INTRODUCTION}

Information design has become increasingly important to process the unprocessed heap of data and information unleashed by information and communication technologies (ICT). Therefore, modern education should provide students with skills and knowledge to use information more proficiently and effectively. ICT learning should offer students a more active role to discover, understand, interpret and use information for its intended purpose rather than just acquiring knowledge passively (Shafipoor, Sarayloo, \& Shafipoor, 2016). One of the approaches to improving students' ability to understand and interpret information is visualization of information which is known as infographics

Citation: Ibrahem, U. M., \& Alamro, A. R. (2021). Effects of Infographics on Developing Computer Knowledge, Skills and Achievement Motivation among Hail University Students. International Journal of Instruction, 14(1), 907-926. https://doi.org/10.29333/iji.2021.14154a 
(Davis, \& Quinn, 2014; Krum, 2013; Mocek, 2012). The purpose of infographics is to develop students' ability to see events and connections between them in new and different ways and to reveal other invisible patterns (Sukerti, \& Sitawati, 2019 ; Matrix, and Hodson, 2014). Infographics have become one of the new trends in today's learning approaches to visualization of knowledge by presenting in visual forms (Sukerti, \& Sitawati, 2019; Ozdamli, \& Ozdal, 2018; Krum, 2013). Toth (2013) states that the history of infographics can be traced back to Egyptian hieroglyphs. Despite all the existing research on the use of new technologies in a higher education classroom, limited research has been conducted on designing and implementation of infographics (IGs) in teaching. This is study significant to highlight the use of infographics either as an information-sharing tool, or as a method of evaluating students' work. This study may inform an understanding of IGs as a natural way to reach students with diverse learning styles, particularly visual learners (Smiciklas, 2012; Lankow et al. 2012; Khalil, 2016; Sukerti, \& Sitawati, 2019).

\section{LITERATURE REVIEW}

New technologies have transformed learning by "visually appealing information resources with concise textual content" (Brigas \& Ramos, 2015; Islamoglu et al., 2015). Infographics generally refer to visualization of data or ideas to convey information in a way that is easily understood and a good infographic should be visualizing a story, a process, or an idea and defining the complicated information clearly along with an eyecatching design (Smiciklas, 2012). Ozdamli, \& Ozdal (2018) Lankow, Ritchie and Crooks (2012) defined infographics as multimedia graphics aiming to present complex information and data in a way that is easy to understand. Lamb and Johnson (2014) and Ozturk (2012) argue that visual infographics include graphics and drawings, diagrams, visualizations, photos, maps, organizers (concept maps, cause and effect modifiers, Venn diagrams, photographs, illustrations, symbols, pictograms and color codes). Lankow, Ritchie, and Crooks (2012), Baglama, et al., (2017); Ozdamli, \& Ozdal (2018) classify infographics as non-interactive, semi-interactive and interactive while Krum (2013) classifies infographics into six categories as static, zooming, clickable, animated, video, and interactive. In addition, infographics present even complex information and processes in such a way that they can be easily understood by creating attention and curiosity.

Infographics can be created through websites hosting software and environments. For example, Lamb and Jhonson (2014), Yildirim, 2016, Dahmash, et al. (2017), Ozdamli, \& Ozdal (2018), and Alford (2019) recommend four main software applications and environment to create infographics which include production software, computer programs, professional design software and online private infographics creation environments. Likewise, Al-Mohammadi (2017) and Lexie, (2018) recommends Adobe Illustrator, Adobe Photoshop, and Web 2.0 web sites for creating infographics. Infographics are used in the environment of e-learning management systems (Afify, 2018) and social media environments ( $\mathrm{Li}, 2013)$. Infographics have been broadly used in business and professional communication courses (Toth, 2013), readers skills (Lazard and Atkinson, 2015), mathematics (Sudakov, Bellsky, Usenyuk, \& Polyakova, 2016), 
geography (Cifci, 2016), science, programming fundamentals skills (Al-Mohammadi, 2017), nursing education (Bradshaw \& Porter, 2017), social sciences and technology (Ozdal, Ozdamli, 2017) and linguistics (Dahmash, Al-Hamid, Alrajhi, 2017).

Infographics are important for communication and transference of information (Smiciklas 2012; Lazard and Atkinson 2015; Alrwele, 2017) and for effective interaction (Shafie, Janier, and Wan-Ahmad, 2009). This finding concurs with Nelson Company, one of the leading Internet research companies which found children ( 2 and 11 years) spending 118 minutes on visuals, teenagers (12 and 17 years old) 132 minutes, while adults 99 minutes on average daily (Lin \& Polaniecki, 2009). With infographics, students can engage in searching, studying, systematic thinking, looking for functional, unique and aesthetic solution methods and doing teamwork (Dur, 2014). More notably, infographics allow information to be visualized and can be prepared in alternative forms (Schroeder, 2004). When textual material delivered with visual forms (images, graphics, diagrams, or charts) in infographic design, it helps to save and retain information (Alqudah, et al., 2019).

Infographics also enable to see relationships between concepts and procedure, convey processes or events effectively, present the content of the course and summarize the subjects learned (Meeusah and Tangkijviwat, 2013; Ozdal, Ozdamli, 2017). Alqudah, et al. (2019), Lamb and Johnson (2014), Eissa (2014) and Simiciklas (2012) argue that infographics help to reduce time to process considerable amount of written information through visual scanning, allow easy comparison of information, make data meaningful by providing analogies, example and themes, make publication and distribution of information via social media easy and help to save information easily.

Infographics are also very effective to transfer complex information to learners by appealing to their multiple senses (Abilock and Williams, 2014; Lamb and Jhonson, 2014) via pie charts, bar graphs, zoom boxes, histograms, icons, line charts, tree diagrams, and even pictures (Parkinson, 2016; Rezaei \& Sayadian, 2015, Wertz \&Saine, 2014). Therefore, infographics may be effective to offer alternative learning materials for students' success (Schrock, 2014) and to help teachers develop learning activities for effective presentation and engaging students in learning (Vanichvasin, 2013). Infographics can also be correlated to students' achievement motivation, their need for success, receiving feedback and experience a sense of accomplishment (Nuhoğlu, \& Akkoyunlu, 2017).

Although new technologies including IGs, designing and implementation of IGs have proven useful for instructional purposes, some researchers have identified some difficulties and challenges. These challenges very often include summarizing the contents of the material and putting it in an IG, developing wireframe for IG, some IGs not suitable for the design principles, negative impact on learning because of mismatch between IGs content and individual characteristics of students, lacking the transfer of ideas and information in weakly designed and non-structured IGs; and challenges of accurate perception by students of the images during the visual communication process. Furthermore, IG designing process entails teachers' additional time adding more 
workload for teachers (Sukerti, \& Sitawati, 2019; Matrix, 2014; Sukerti, \& Sitawati, 2019; Ozdamli, \& Ozdal, 2018; and Daud, Abdullah \& Harun, 2015).

\section{Research Objectives}

The primary objective of this paper is to determine the relationships between students' score and their use of e-learning, computer skills and their achievement motivation. More specifically the study aims to investigate the relationships between the use of static infographics (SIs) and animated infographics (AIs) and overall achievement and motivation in the Preparatory-Year undergraduate male and female students. The research was based on the perceptions gathered from experts, instructors and Preparatory-Year students who participated in the implementation of SIs and AIs. Before the implementation of the SIs and AIs, educational objectives, elements of educational content, standardized tests, educational message and media elements, script design and learning implementation strategy were selected. The design of the study followed the Elgazzer Model (2014).

The key learning objectives of SIs and AIs is to develop students' learning experience and their ability to choose, develop and integrate visual materials during instructions (Bicen, Beheshti, 2017). When exposed to huge amount of information, students might lack motivation which in turn may lead to lower achievement. This study, therefore, endeavors to answer the following research questions:

1. What is the effect of SIs on male and female students' score in relation to their achievement?

2. What is the effect of SIs on male and female students' score in relation to their elearning and computer skills?

3. What is the effect of Ais on male and female students' score in relation to their achievement?

4. What is effect of AIs on male and female students' score in relation to their elearning and computer skills?

5. What is the effect of SIs and AIs on male and female students' score in relation to their e-learning and computer skills?

6. What is the difference between the effect of SI and the effect of AIs on students' score in relation to their achievement?

7. What is the difference between the effect of SI and the effect of Ais on students' score in relation to increasing their achievement motivation?

8. What is the effect of SIs on male and female students' score in relation to increasing their achievement motivation?

9. What is the effect of Ais on male and female students' score in relation to increasing their achievement motivation?

\section{METHOD}

\section{Method, Variables and Sample}

Experimental method was used to investigate the effect of Sis and AIs, infographic designing types on developing both achievement and achievement motivation among UOH Students. The independent variables in this research consisted of the AIs and Sis 
embedded learning content while the dependent variables were achievement of elearning and computer skills and achievement motivation while classifying variables among male and female participants. Research sample consisted of 80 male and female students studying e-learning and computer skills course in the second semester of 2018/2019 at the UoH. Measurement tools included the observation list, achievement test and achievement motivation scale.

Table 1

Experimental Design

\begin{tabular}{|c|c|c|c|c|}
\hline Group & No/kinds & Pre-test & Treatment & Post test \\
\hline$(1)$ & 20/male & \multirow{4}{*}{$\begin{array}{l}\text { Knowledge } \\
\text { test } \\
\text { Motivation } \\
\text { scale }\end{array}$} & studied learning & \multirow{2}{*}{$\begin{array}{ll}- & \text { Knowledge test } \\
- & \text { Motivation scale }\end{array}$} \\
\hline (2) & 20/female & & content using (SI). & \\
\hline (3) & 20/male & & studied learning & Observation \\
\hline (4) & 20/ female & & content using (AI). & List. \\
\hline
\end{tabular}

\section{Procedure}

The researchers designed 4 experimental groups for learning content through the two infographics' types: the learning content in the form of SIs and AIs. All experiments were conducted via the Blackboard platform. The infographics-based e-learning program was developed according to the stages of Elgazzer Model (2014) developed for educational design.

\section{Stage One: Application of Achievement Pre-Test}

Achievement pre-test was applied among Preparatory Year students (17-18 years age group) at the $\mathrm{UOH}$ to assess their ability and experience to use computer and to identify learners' cognitive skills, basic skills and achievement motivation needs. Before preparing the final version, seven major themes with 78 sub-skills were identified followed by the first draft of the list. Then, the experts were consulted to determine the importance and relevance of the main themes and sub-skills. The final list included 10 criteria for infographic design. The researchers also ensured that the learning environment was appropriate with the specifications set for devices used. Study load and inadequate experience of sample students were identified as major challenges in this stage. Finally, SIs and AIs based learning program was applied in the second semester of the academic year 2018/2019 from 5/4/2019 to 30/5/2019.

\section{Stage Two: The Design}

Developing Preparatory Year students' e-learning and computer skills was identified as the main educational objectives of the study. The elements of educational content, learning objectives and learning experiences were matched with the objectives and the learning units. The standardized test was designed appropriately to measure students' learning outcomes. Appropriate media elements were selected to match the learning experiences of the students to enable them to produce infographics. Educational message of the media elements was prepared according to students' ability and interests. 'The Scenario' and 'the Storyboard' (static and animated images as used in the modified Elgazzer Model) were used in the first and second stages, respectively. Educational message and media elements were designed following the modified Elgazzer Model 
(2014), with the procedure of: Acquisition of the learner's attention - Show stimuli Provide feedback- Introduce the learner to learning objectives - Guide learning Performance measurement, diagnosis and treatment - Recall previous learning - Edit and activate the learner response - Help the learner to retain what has been learned and transmission of learning. The infographic multimedia scenario was used for script design. Finally, learning implementation strategy was developed.

Table 2

Shows the general and behavioral objectives of the educational program

\begin{tabular}{lll}
\hline Module & General Objective & $\begin{array}{l}\text { Behavioral } \\
\text { objectives }\end{array}$ \\
\hline I & familiarizing the sample with the concepts and skills of e-learning & 11 \\
\hline II. & Students' knowledge of ICT concepts & 8 \\
\hline III. & Giving the sample the skills to deal with the Internet and networking & 4 \\
\hline IV & Giving the ability to use the operating system Windows 10 & 7 \\
\hline V & Giving students the ability to use a word processor Word 2016 & 7 \\
\hline VI & Giving students the ability to use electronic scales using Excel & 6 \\
\hline VII & Giving students the ability to use PowerPoint presentations & 6 \\
\hline
\end{tabular}

Stage Three: The Production

Media were selected according to the modified Elgazzer Model (2014). The tracks included acquisition (pre-produced infographic), modification (modify producers' infographic) and new production (producing entirely new infographic). The sources for the production of SI and AI were selected from still images, drawings, animation, and video and written texts.

\section{Stage Four: The Evaluation}

Infographics were sent to a group of educational technology specialists to ensure its reliability and validity. The researchers incorporated feedback for amendments for final evaluation. Then, the experiment was tested among a sample of five students from the $\mathrm{UoH}$ for validity and reliability of the program and making necessary adjustments before the experimental application. Finally, the research experiment was applied to experimental groups. Then data were collected using appropriate tools and analyzed statistically.

\section{Stage Five: Final Application}

The learning content of SIs was uploaded on the Blackboard platform. The research sample was divided into four groups as: Two groups (male and female) studied the learning content using SIs and two groups (male and female) studied the learning content using AIs. At a face-to-face meeting with students, instructors informed them about learning activities and tasks, evaluation methods, e-content of the course and methods of learning through the e-learning platform. Then, the students completed the assignments and tasks and submitted them electronically to the teacher for evaluation and grading. Tests and measurement tools for achievement test included observation scale for e-learning and computer skills and achievement motivation scale. 


\section{Achievement Test}

The achievement test (Hassan, 2016; Omar, 2016; Khalil, 2016; Singh \& Jain, 2017) was designed to measure the ability of the study sample of e-learning and computer skills by applying it pre and post-tests. First, educational objectives were identified to be measured by the test. The educational objectives clearly defined behavioral outcomes leading to final behavior. The initial test was prepared with scores (50 questions with 50 score) and clear test instructions. To determine the validity of the test, a specification table was prepared, experts were consulted to ensure the validity of the test and the stability and internal coherence of the test was confirmed by measuring the internal consistency coefficient $(\alpha)$ on the results of the post-application of the research sample using the statistical software package (SPSS) as in Table 3.

Table 3

Results of the calculation of stability factor $(\alpha)$ for the post-test

\begin{tabular}{llll}
\hline Stability coefficient & Sample number & Number of items & The value \\
\hline The coefficient of $\alpha$ & 6 & 50 & 0.92 \\
\hline
\end{tabular}

The table shows the high rate of stability of the test (0.92) indicating the accuracy.

\section{e-learning and Computer Skills Observation Scale}

The first draft of the scale of 45 skills distributed over seven areas gleaned from previous studies to assess sample students' e-learning and computer skills. The scale contained the most statistically significant 42 statements distributed over seven areas. The scale was applied individually by the instructor. Each student was required to submit a project and the teacher analyzed the performance skills of the students either during the practice session, or the project. A 5-D response scale with excellent, very good, good, acceptable, and weak was applied and then the Scale statements were corrected by giving (5) degrees for excellence, (4) for very good, (3) for good, (2) for acceptable, (1) for unacceptable. To ensure the validity the scale, the list was presented to a group of experts. Then necessary changes were made on the scale incorporating feedback from the experts. At the end, the scale was piloted on a survey sample of 18 male and female students from Hail University (not the study sample) in order to determine the stability of the scale. It was done by using the equation alpha Kronbach 0.83 which indicates that the scale of the degree of stability acceptable.

The coefficient of discrimination of the singular = coefficient of ease $\mathrm{X}$ coefficient of difficulty.

It is considered the best single coefficient $(0.25)$ which is equal to the highest value of this coefficient, and the coefficient of discrimination of the paragraphs between $(0.18$ 0.24), which is acceptable coefficients statistically.

Coefficient of stability was determined by re-applying the scale "Pearson equation" which was the coefficient of stability 0.80 which indicates the stability of the scale and its suitability for use. The e-learning and computer skills scale consisted of 42 items. 


\section{Achievement Motivation Scale}

The scale and measurement of achievement motivation (Singh, \& Jain, 2017; Ciftci, 2016; Darwish, 2015; Aisami, 2015; Lynn, 1969) was prepared and applied to a sample of students of the UOH. The first draft of the scale consisted of 24 items. After the analysis of the statements statistically and choosing the most statistically significant 20 items, the scale was used individually by students with a 5-D scale: excellent, very good, good, acceptable, and weak. Then, scale statements were corrected by giving (5) degree for excellence, (4) for very good, (3) degree for good, (2) for acceptable, (1) for unacceptable. To ensure the validity, the scale was assessed by a group of experts who provided feedback for improvement. Later, the scale was piloted among a sample of 18 male and female students from the $\mathrm{UoH}$ (other than the study sample) in order to determine the stability of the scale: the coefficient of stability using the equation alpha Kronbach (0.79) which indicates that the scale of the degree of stability acceptable. Coefficient of discrimination was calculated from the equation as before. Coefficient 0.21 was considered the best single coefficient and statistically acceptable one.

\section{FINDINGS AND DISCUSSION}

Overall, the study informed an understanding that infographics could be a more effective method of engaging students in learning content than traditional learning methods. For this study, SPSS V.22.1 software was used to analyze data, including an independentsamples t-test, Cronbach's Alpha, and Pearson's Correlation. Item difficulty indices and item discrimination indices were also calculated. The accepted significance was determined to be $p$.

Q.1. What is the effect of SIs on male and female students' score in relation to their achievement?

According to Table (4), the value of "T" was 4.81 at the degree of freedom 38 , and the computerized significance 0.000 . Since this calculated significance was less than 0.05 , there was a statistically significant difference between the mean scores of the sample in the post test for achievement in favor of female students. We noticed as in the figure $3 \mathrm{a}$ high impact size and its value 0.379 .

Table 4

Shows the effect of SIs on male and female students' score in relation to their achievement.

\begin{tabular}{llllllll}
\hline Gender & N & Mean & Std & Df & T & Sig & Effect sizes \\
\hline Male & 20 & 32.15 & 2.23 & 38 & -4.81 & 0.000 & 0.379 \\
\cline { 1 - 5 } Female & 20 & 35.40 & 2.04 & & & Sig. & High \\
\hline
\end{tabular}

This can be compared with Roehling, Kooi, Dykema, Quisenberry and Vandlen (2010) who found that students raised in a multimedia environment shifted their attention rapidly from one source of information to another. As a result, students tend to have a low tolerance for boredom and require high levels of stimulation to remain focused.

Gallagher (2017) explained how learners perceived instructor-provided summary infographics as useful and appealing for retaining, clarifying and understanding learning 
concepts. The students reported that these concepts were less motivating before the use of infographics. They believed that infographics increased their motivation because visual representation helped them to understand the concepts. This finding concurs with Ciftci, 2016; Ozdal, Ozdamli, (2017); Alrwele, (2017) who reported that infographics were effective for improving student achievement.

Q.2. What is the effect of SIs on male and female students' score in relation to their e-learning and computer skills?

Table 5

Shows the effect of SIs on male and female students' score in relation to their e-learning and computer skills.

\begin{tabular}{llllllll}
\hline Gender & $\mathrm{N}$ & Mean & Std & Df & T & Sig & Effect sizes \\
\hline Male & 20 & 13.40 & 1.75 & 38 & -2.39 & 0.022 & 0.130 \\
\cline { 1 - 5 } Female & 20 & 14.60 & 1.39 & & & Sig. & Moderate \\
\hline
\end{tabular}

Table (5) shows the value of "T" as 2.39 at the degree of freedom 38 and the computerized significance was 0.130 . Since the calculated significance was less than 0.05 , there was a statistically significant difference between the mean scores of the study sample in the post-test for e-learning and computer skills in favor of female students. We noticed a moderate impact size and its value 0.130 as shown in Figure 4.

This can be aligned with the findings that infographics are effective for improving skills (Alrwele, 2017; Bicen \& Beheshti, 2017; Hassan, 2016). Ibrahim (2017) also reported the impact of an educational program based on infographic technology for developing visual thinking skills. Likewise, Abdul Rahman (2018) asserted that designing a webbased learning environment based on (SI) has an impact on the development of user interface design skills.

Q.3. What is the effect of AIs on male and female students' score in relation to their achievement?

Table (6) represents the value of "T" as 2.73 at the degree of freedom 38, and the computerized significance 0.010 . Since this calculated significance was less than $(0.05)$, there was a statistically significant difference between the mean scores of the study sample in the post-test for e-learning and computer skills in favor of male students. We noticed a high impact size and its value 0.164 as represented in Figure 5.

Table 6

Shows the effect of AIs on male and female students' score in relation to their achievement

\begin{tabular}{llllllll}
\hline Gender & $\mathrm{N}$ & Mean & Std & Df & T & Sig & Effect sizes \\
\hline Male & 20 & 34.65 & 2.21 & 38 & 2.73 & 0.010 & 0.164 \\
\cline { 1 - 5 } Female & 20 & 32.85 & 1.95 & & & Sig. & High \\
\hline
\end{tabular}

This result can be compared with Allen and Seaman (2014) who stated that learners prefer materials with high visual and interactive features for educational activities. Students exhibited better retention of infographics rather than in other textual forms, making infographics very powerful tools for information uptake (Yildırım et al., 2016; 
Khalil, 2016). Alqudah, D. et al. (2019) also found infographics having a positive impact on students' interaction and their skills.

Q.4. What is effect of AIs on male and female students' score in relation to their elearning and computer skills?

Table 7

Shows the effect of AIs on male and female students' score in relation to their e-learning and computer skills

\begin{tabular}{llllllll}
\hline Gender & $\mathrm{N}$ & Mean & Std & Df & T & Sig & ETA Effect sizes \\
\hline Male & 20 & 17.40 & 1.67 & 38 & 3.13 & $\begin{array}{l}0.003 \\
\text { Sig. }\end{array}$ & $\begin{array}{l}0.204 \\
\text { High }\end{array}$ \\
\hline Female & 20 & 15.50 & 2.14 & & & &
\end{tabular}

Table (7) shows the value of "T" (3. 13) at the degree of freedom 38 and the computerized significance 0.003 . Since this calculated significance was less than 0.05 , there was a statistically significant difference between the mean scores of the study sample in the post test for the e-learning and computer skills test in favor of male students as shown in figure ). We also noticed a high impact size and its value 0.204.

This result also aligns with Jaber (2017) who found the effectiveness of infographic in developing the skills of preparing portfolio. Ibrahim (2017) also found the high impact of an infographic-based educational program in developing visual thinking skills. Both of Abdul Rahman et al., (2016); Darwish and Al-Dukhani, (2015); Mansour's (2015)found infographic effective to develop visual thinking skills, visual culture skills and design technology skills. On the other hand, Bicen and Beheshti (2017) show that male students are more motivated than female students to learn by infographics.

Q.5. What is the effect of SIs and AIs on male and female students' score in relation to their e-learning and computer skills?

Table 8 depicts the value of "T" is 5.72 at the degree of freedom 38 , and the computerized significance (0.000). Since this calculated significance is less than 0.05 , there was a statistically significant difference between the mean scores of the study sample in the post-application for the e-learning and computer skills test (figure 7) in favor of AI.

Table 8

Shows the effect of SIs and AIs on male and female students' score in relation to their elearning and computer skills

\begin{tabular}{llllllll}
\hline Infographics & $\mathrm{N}$ & Mean & Std & Df & T & Sig & Effect sizes \\
\hline Static & 40 & 14 & 1.68 & 78 & -5.72 & 0.000 & --- \\
\cline { 1 - 5 } & 40 & 16.45 & 2.12 & & & Sig. & \\
\hline
\end{tabular}

The findings of similar studies informed that infographics contributed to higher order learning skills (Schrock, 2014), enhanced student's success skills (Saurbier, 2014) and developed high order thinking skills (Fowler, 2015).

The results have also demonstrated that SI has more effects on developing skills of designing and producing visual learning materials and recognizing its elements and principles compared to the animated type (Afify, 2018). There is a difference between 
the average scores of the experimental students studying SI and studying AI in the postapplication of the measure of digital citizenship skills in favor of AI (AlSaiyed, 2018).

Q.6. What is the difference between the effect of SIs and the effect of AIs on students' score in relation to their achievement?

Table (9) represents the value of "T" as 0.045 at the degree of freedom 38, and the computerized significance 0.964 .

Table 9

Shows the difference between the effect of SIs and the effect of AIs on students' score in relation to their achievement

\begin{tabular}{|c|c|c|c|c|c|c|c|}
\hline Infographics & $\mathrm{N}$ & Mean & Std & $\mathrm{df}$ & $\mathrm{T}$ & Sig & Effect sizes \\
\hline Static & 40 & 33.78 & 2.67 & 78 & 0.045 & 0.964 & --- \\
\hline Animated & 40 & 33.75 & 2.25 & & & Not Sig. & \\
\hline
\end{tabular}

This can be compared with the results of previous which established that visual materials could have a positive impact on the learning of psychomotor skills (Gultekin 2009). Similarly, the use of infographics in education had a positive impact on the academic success (Ozdal, Ozdamli, 2017). Likewise, infographics strategy was found as an effective approach to teaching programming fundamentals on developing analytical thinking skills(Al-Mohammadi, 2017).

Ahmed (2018) also found that the positive effect of SIs in the development of visual learning skills for AIs. However, Darwish and Dukhani (2015) argue that the animated effect may produce greater than the static effect in the development of performance skills.

Q.7. What is the difference between the effect of SIs and the effect of AIs on students' score in relation to increasing their achievement motivation?

The value of "T" in Table (10) is 4.58 at the degree of freedom (38) and the computerized significance 0.000 . Since this calculated significance was less than 0.05 , there was a statistically significant difference between the mean scores of the study sample in the post application for increasing achievement motivation (figure 9) in favor of AIs.

Table 10

Shows the difference between the effect of SI and the effect of AIs on students' score in relation to increasing their achievement motivation

\begin{tabular}{|c|c|c|c|c|c|c|c|}
\hline Infographics & $\mathrm{N}$ & Mean & Std & $\overline{\mathrm{Df}}$ & $\mathrm{T}$ & Sig & Effect sizes \\
\hline Static & 40 & 33.40 & 2.62 & 78 & -4.58 & 0.000 & 0.356 \\
\hline Animated & 40 & 36.10 & 2.66 & & & Sig. & High \\
\hline
\end{tabular}

This finding can be explained as using visual materials when teaching languages had influenced students' motivation, success and attitude positively (Canning-Wilson 2011). Similarly, İslamoğlu et al. (2015) reported that Infographics increased positive attitudes towards the lesson. Likewise, visualization attracts attention, increases motivation and helps students to organize information (Presmeg, 2014). 
Q.8. What is the effect of SIs on male and female students' score in relation to increasing their achievement motivation?

Table (11) illustrates that the value of "T" is 0.000 at the degree of freedom 38 and the computerized significance 1.000. The calculated significance was more than 0.05 .

Table 11

Shows the effect of SIs on male and female students' score in relation to increasing their achievement motivation

\begin{tabular}{llllllll}
\hline Gender & $\mathrm{N}$ & Mean & Std & Df & T & Sig & Effect sizes \\
\cline { 1 - 4 } Male & 20 & 33.40 & 2.64 & 38 & 0.000 & 1.000 & - \\
\cline { 1 - 5 } Female & 20 & 33.40 & 2.66 & & & Not Sig. & \\
\hline
\end{tabular}

This finding also indicates that infographics are an effective way in improving positive attitudes towards the lecture (Ciftci, 2016). Alqudah's study (2019) also shows that infographics have a positive and strong impact on students' interaction and perception.

Matrix and Hodson (2014) reported the utilization of infographic to motivate students learning. The result reveals that there is a significant difference in achievement motivation between male and female dyscalculic students taught by the traditional design. The mean value of achievement motivation of female dyscalculic taught by the traditional design of mathematics was found greater than males.

Q.9. What is the effect of $\mathrm{AI}$ on male and female students' score in relation to increasing their achievement motivation?

The value of "T" as presented in Table (12) is 0.12 at the degree of freedom 38, and the computerized significance (0.907). This calculated significance was more than 0.05 .

Table 12

Shows the effect of AI on male and female students' score in relation to increasing their achievement motivation

\begin{tabular}{llllllll}
\hline Gender & $\mathrm{N}$ & Mean & Std & df & T & Sig & Effect sizes \\
\hline Boys & 20 & 36.15 & 2.56 & 38 & 0.12 & 0.907 & - \\
\cline { 1 - 5 } Girls & 20 & 36.05 & 2.82 & & & Not Sig. & \\
\hline
\end{tabular}

These results align with Comello ML; Qian X, Deal AM, Ribisl KM, Linnan LA \& Tate DF (2016) who found infographics effective for developing comprehension, positive attitudes toward the information, positive emotional responses. Similarly, Kibar and Akkoyunlu (2017) revealed that students could be motivated to generate their own content through using infographics. Alqudah's study (2019) also represents that infographics have a positive impact on students' interaction and perception. Likewise, Ismail (2016) emphasized that the use of interactive/ static infographic has the effect of developing positive attitudes towards achievement.

Overall, the current study revealed that the use of IGs had a more positive effect on engaging students in learning content than traditional learning methods. Students' active participation in learning processes may be attributed to their activated sensory organs through IGs. Moreover, visualization of texts and images used in infographics may help students to understand and retain content message in long term memory. The use of IGs 
seemed to help students to reinforce existing knowledge, show relationship between concepts, explain processes and events, present lecture content and summarize the information through infographics (Meeusah and Tangkijviwat, 2013). Graphic representations and visual data may have enabled users to communicate a message that can be perceived widely across diverse audiences (David and Glore, 2010; Mocek, 2012).The results of this study are also consistent with visual research studies that demonstrate convincing justification for the use of infographics in facilitating students' understanding of the content being taught. The scientists at the Massachusetts Institute of Technology discovered that vision is the largest part of brain physiology, and that approximately $50 \%$ of the brain's power is directed directly or indirectly towards the function of vision, the brain's processing of imaging information (infographics) is less complicated than its treatment of raw texts (Ibrahim, 2017 ).

Since IGs provide alternative instructional tools for instructors, they can be more effective than written texts and oral presentations for teaching especially complex concepts. The result concurs with the results of learning retention and efficiency (Elena ,et al., 2017, Dunlap \& Lowenthal, 2016; Abdul Rahman, et al., 2016). That learning through visual texts makes learning more efficient, effective and, IGs offer a way to present complex and intense content in an attractive and interesting way, and enables better understanding and assimilation of knowledge to improve the ability of the human visual system to see different patterns and trends. In addition, as evidenced in this study, infographics may be promising instructional instruments that seem to match the interests of digital age students and break the monotony of traditional mode of teaching. The current study might contribute to the visual communication theory, specifically using infographics for educational aims and reforms considering students' needs, ability, gender, age and the context. The experience of designing an IG can serve to enrich students' understanding of their own disciplinary specific requirements and offer an opportunity to engage students in reflecting upon questions of audience (Chong, 2012; Sukerti, \& Sitawati, 2019).

Based on the analysis of previous studies (Krum, 2013; Baglama, Yucesoy, Uzunboylu, \& Özcan, 2017; Sukerti, \& Sitawati, 2019) and the results from the current study, the researchers would like to make some important recommendations. First, teachers will benefit from professional development programs which develop skills and knowledge for designing lessons using educational infographics and implementing them in classroom or e-learning environments. The increasing use of infographics as a strategy of teaching is often thought to be effective for developing personalized learning of individual students for developing their cognitive skills and performance. Likewise, students learning experience can be further improved by involving more technical information, interaction design and interface design in interactive IG projects this is as previous studies pointed (Ciftci, 2016; Shafipoor, Sarayloo and Shafipoor, 2016). Also, we discovered that presenting intense and complex information on a certain topic via IGs created a positive impact on students' skill and experience in a more understandable and visual manner. Similar results were reported in the studies elsewhere (Sukerti, \& Sitawati, 2019 ; Matrix, 2014; Li, Carberry, Fang, McCoy and Peterson (2014). 
Furthermore, the results can also be explained in the light of learning theories. Our study also revealed that breaking down content into small steps in static or animated IGs in the form of graphics, arrows, pictures, or texts may have enabled students to augment their focus of attention and encode information more efficiently. This type of IG supports information processing theory, or media richness theory which implies the richness of visual communication media to appeal senses for encoding information into human memory, particularly increasing the capacity of long term memory (Khamis, 2013). The richness of information may even provide stimuli to improve the educational task performance more efficiently (Al-Dariush, \& Abdel-Alim, 2020). Improvement of task performance observed in this study is also consistent with the interpretations of cognitive efficiency theory, which emphasizes the learning media's potential to attract personal focus and address multiple information signals simultaneously (Ibrahim, 2017).

Although the current study was significant to illustrate the value of IGs in terms of providing high visual and interactive features of information, and developing computer skills and e-learning, positive attitude to learning and achievement motivation, we state mainly three limitations of the study. First, the sample population consisted of a small number of students which may limit the generalization of the study. Thus, we recommend a bigger sample of population that might be generalized to other groups of learners with varied learning styles and specializations in Saudi Arabia and other parts of the world. Next, this study attempted to investigate the effects of only SIs and AIs for developing knowledge and skills achievement and increasing the achievement motivation. Therefore, future studies may illuminate more insight if they investigate the other forms of IGs and their impact on information uptake by students. Finally, the field of IGs will benefit from future studies showing the relationships between IQ and uptake of digital skills which was beyond the scope of this study.

\section{CONCLUSION}

The results of this study indicate that infographics are effective for improving students' achievement, e-learning and computer skills and achievement motivation. This study highlights that infographics have considerable potential in education to enhance students' skills and motivation. In addition, this study also revealed that the use of static infographic has a greater effect on female student learning while animated infographic was effective for male student learning. Furthermore, infographics has been found effective to process and scan significant amount of information more easily and efficiently and may help teachers to teach such information effectively by employing suitable components of infographics. Educational programs at higher education may design lessons integrating IGs to leverage the maximum potential of learning. This study could be replicated in various educational settings with students with different learning styles and specializations at different academic levels. This study is significant to illustrate that IG works should involve more technical information and areas like interaction design and interface design to afford visual richness for increasing students' potential for information processing. IGs may provide powerful instructional tools for presenting complex information with media richness to facilitate students to understand lessons and improve learning retention which might be deficit in written texts. Although this study may contribute to the understanding of AI and SI in relation to the 
development of computer skills, e-learning, motivation and positive attitude towards learning, we also believe that future studies exploring the relationships between learning and other forms of IGs would further illuminate and explain how learners of varied IQs, learning styles and levels may improve their learning.

\section{ACKNOWLEDGMENTS}

The authors acknowledge the support provided by Deanship of Scientific Research at the University of Ha'il, Ha'il, KSA.

The authors acknowledge the support provided by Deanship of Scientific Research at the UOH, KSA, The search (No. 0160619) funded by Scientific Research. The funding source had no involvement in any aspect of the study design, delivery, or publication.

\section{FUNDING}

The search (No. 0160619) funded by Scientific Research at the UOH, Hail, KSA. The funding source had no involvement in any aspect of the study design, delivery or publication.

\section{REFERENCES}

Abdul Rahman, A., Al-Sayed, A. A., and Okah, E. S. (2016.) An analytical study of infographics and its role in the educational process in a context Fine text formulations (the relationship of writing to image). Research Journal of Education Art and Art Faculty of Art Education - Helwan University, No. 47 - 1

Abdul Rahman, M. K. (2018). Interaction between the two types of infographic design "fixed and Animated" and e-learning platforms "black Board, WhatsApp" and its impact on the development of visual learning design skills and the perception of its elements. Journal of Education for Educational, Psychological and Social Research, No. 177, Vol. 1 (258).

Abilock, D. \& Williams, C. (2014). Recipe for an Infographic. Knowledge Quest 43(2), 45-55.

Afifi, M. A. (2018). The interaction between the "fixed and mobile" infographics design patterns and the two e-learning platforms "Al-Balad Board, WhatsApp" and its impact on developing visual learning design skills and realizing its components.

Afify, M. K. (2018). The effect of the difference between infographic designing types (static vs animated) on developing visual learning designing skills and recognition of its elements and principles. International Journal of Emerging Technologies in Learning (iJET), 13(09), 204-223.

Ahmed, E. A. (2018). The Effect of Different Types of Educational Infographic (Individual/ Collaborative) through Wiki in Developing Participatory Learning Skills and Analytical Thinking in the Students of Industrial Education Faculty. Journal of the Faculty of Education, Al-Azhar University, Issue 180. 
Aisami, S. R. (2015). Learning styles and visual literacy for learning and performance.

Procedia - Social and Behavioral Sciences, 176, 538-545. doi:10.1016/j.sbspro.2015.01.508.

Al-Dariush, A. A, \& Abdel-Alim, R. A. (2020). Infographic in educational technology, King Saud University House for Publishing.

Alford, K. (2019) The Rise of Infographics: Why Teachers and Teacher Educators Should Take Heed. Teaching/Writing: The Journal of Writing Teacher Education, 7(1), 7.

Allen, I. E., \& Seaman, J. (2014). Grade Change: Tracking Online Education in the United States. Babson Survey Research Group.

Al-Mohammadi, N. (2017). Effectiveness of using infographics as an approach for teaching programming fundamentals on developing analytical thinking skills for high school students in the city of Makkah in Saudi Arabia. Global Journal of Educational Studies, 3(1), 22-42.

Alqudah, D., Bidin, A. B., \& Hussin, M. A. H. B. M. (2019). The Impact of Educational Infographic on Students' Interaction and Perception in Jordanian Higher Education: Experimental Study. International Journal of Instruction, 12(4), 669-688.

Alrwele, N. S. (2017). Effects of Infographics on Student Achievement and Students' Perceptions of the Impacts of Infographics. Journal of Education and Human Development, 6(3), 104-117.

AlSaiyed, A. A. (2018). The effect of different Static and Animated infographic patterns on the development of digital citizenship skills among students of higher computer institutes, Education Technology - Studies and Research, 35, 52-1.

Baglama, B., Yucesoy, Y., Uzunboylu, H., \& Özcan, D. (2017). Can infographics facilitate the learning of individuals with mathematical learning difficulties. International Journal of Cognitive Research in Science, Engineering and Education, 5(2), 119-128.

Bicen, H., \& Beheshti, M. (2017). The psychological impact of infographics in education. BRAIN. Broad Research in Artificial Intelligence and Neuroscience, 8(4), 99-108.

Bradshaw, M. J., \& Porter, S. (2017). Infographics: A new tool for the nursing classroom. Nurse educator, 42(2), 57-59.

Brigas, J. M. F., \& Fernandez, L. F. R. (2015). Infographics as an auxiliary tool for teaching/learning. Revista de Comunicación de la SEECI, 178-184.

Canning-Wilson, C. (2001). Visuals and language learning: Is there a connection. ELT Newsletter, 48, 1-18. Retrieved on November 11, 2016, from www.eltnewsletter.com/back/Feb2001/art482001.htm .

Cifci, T. (2016). Effects of infographics on students achievement and attitude towards geography lessons. Journal of Education and Learning, 5(1), 154-166. 
Comello, M. L. G., Qian, X., Deal, A. M., Ribisl, K. M., Linnan, L. A., \& Tate, D. F. (2016). Impact of game-inspired infographics on user engagement and information processing in an eHealth program. Journal of medical Internet research, 18(9), e237.

Dahmash, A. B., Al-Hamid, A., \& Alrajhi, M. (2017). Using infographics in the teaching of linguistics. Arab World English Journal (AWEJ) Volume, 8.

Darwish, A. M. Ahmed, \& Al-Dukhani, A. E. (2015). Pattern of introducing (static / mobile) infographics across the web and their effect on developing visual thinking skills among autistic children and their attitudes towards it. Education Technology- Egypt, Vol. 25, G2, 364-2

Darwish, A. M.; El-Dakhni, A. A. (2015). Patterns of Avographic Presentation on the Web and Their Effect on Developing Visual Thinking Skills and Attitudes Towards Autism Children, Educational Technology, Egypt, 25( 2), 265-364.

Darwish, M. S. (2015). The Effectiveness of Using Infographic to Learn the Skill Performance and Cognitive Achievement of the Long Jump Competition. Scientific Journal of Physical Education and Sport, Vol. 77 ، 265- 364.

David, A., \& Glore, P. (2010). The impact of design and aesthetics on usability, credibility, and learning in an online environment. Online Journal of Distance Learning Administration, 8(4).

Davis, M., \& Quinn, D. (2013). Visualizing text: The new literacy of infographics. Reading today, 31(3), 16-18.

Dur, B. I. U. (2014). Data visualization and infographics in visual communication design education at the age of information. Journal of Arts and Humanities, 3(5), 39-50.

Eissa, M. (2014). What is the Infographic? Definition, Tips and Free Tools. Retrieved October 2, 2018, from http://xn------lzecaacca1agqu6awd7etd9hde5br5cm6bt6bf.

Gallagher, E., S., O’Dulain, M., O’Mahony, N., Kehoe, C., McCarthy, F., \& Morgan, G. (2017). Instructor-provided summary infographics to support online learning. Educational Media International, 54(2), 129-147.

Dunlap, J. C., \& Lowenthal, P. R. (2016). Getting graphic about infographics: Design lessons learned from popular infographics. Journal of Visual Literacy, 35(1), 42-59.

Elgazzar, A. E. (2014). Developing e-learning environments for field practitioners and developmental researchers: a third revision of an ISD model to meet e-learning and distance learning innovations. Open Journal of Social Sciences, 2(2), 29-37.

Gultekin, B. (2009). The Impact of Methods with Visual Materials on the Learning of Psychomotor During the Education of Basic Basketball Skills in the Physical Education Classes at 5th and 6th Grades. Master Thesis. Marmara University, Educational Sciences Institute, İstanbul.

Hassan H. G. (2016). Designing Inforgraphics to Support Teaching Complex Science Subject: A Comparison Between Static and Animated Infographics, Doctoral Dissertation, IOWA STATE University. 
Ibrahim, R. A. (2017). The effect of an educational program in science based on infographics on acquiring scientific concepts and developing visual thinking skills and usability for hearing impaired students in the elementary stage. 340-, Journal of Education for Educational, Psychological and Social Research, 175, Part 3411.

Islamoglu, H., Ay, O., Ilic, U., Mercimek, B., Donmez, P., Kuzu, A., \& Odabasi, F. (2015). Infographics: A New Competency Area for Teacher Candidates. Cypriot Journal of Educational Sciences, 10(1), 32-39.

Ismail, A. M. M. (2016). The Use of Interactive/ Static Infographics and its Effect on the Development of Educational Achievement among Educational Technology Students and their Attitudes Toward it. Education Technology: Studies and Research, Egypt 1(28), 111-189.

Jaber, S. A. (2017). The Effectiveness of an Infographic-Based Training Program in Developing the Skills of Preparing the Portfolio and the Attitude Toward It for Students Teachers in the Schools of Intellectual Education in Al-Ahsa. Arab Journal for Studies and Researches in Educational and Human Sciences - Dr. Hanan Darwish for logistics and applied education, 11-50.

Khalil, A. A. (2016) "Static / Motion / Interactive" educational infographic patterns and its effect on achievement and the efficiency of mathematics learning among elementary stage students with simple intellectual disabilities. Education Journal for Educational, Psychological and Social Research, p. 169, C3, 321 - 272.

Krum, R. (2013). Cool infographics: Effective communication with data visualization and design. Indianapolis, IN: John Wiley \& Sons, Inc.

Lamb, A., \& Johnson, L. (2014). Infographics part 1: Invitations to Inquiry. Teacher Librarian, 41(4), 54-63.

Lankow, J., Ritchie, J., \& Crooks, R. (2012). Infographics: The power of visual storytelling. John Wiley \& Sons.

Lazard, A., \& Atkinson, L. (2015). Putting environmental infographics center stage: The role of visuals at the elaboration likelihood model's critical point of persuasion. Science Communication, 37(1), 6-33.

Lexie K. (2018). Designing effective infographics, Nielsen Norman Group world Leaders in research-based user experience, Retrieved on August 8, 2018, from https://www.nngroup.com/articles/designing-effective-infographics/.

Li, A. (2013). Rise of infographics: marketing in the social-media age. Retrieved may 1, 2018, from http://mashable.com/2013/01/26/infographics-marketing/.

Li, Z., Carberry, S., Fang, H., McCoy, F. K., \& Peterson, K. (2014). Infographics retrieval: A new methodology, 19th International Conference on Applications of Natural Language to Information Systems, L'Université de Montpellier, 18 - 20 June 2014, Montpellier. 
Lin, C. C., \& Polaniecki, S. (2009). From Media Consumption to Media Production: Applications of YouTube ${ }^{\mathrm{TM}}$ in an Eighth-Grade Video Documentary Project. Journal of Visual Literacy, 28(1), 92-107.

Lynn, R. (1969). An achievement motivation questionnaire. British Journal of Psychology, 60(4), 529-534.

Mansour, M. M. (2015). The Impact of Using Marzano's Infographic Technology on the Development of Some Concepts of Cloud Computing and the Habits of Productive Mind in the Students of the Faculty of Education, Journal of the Faculty of Education in Assiut, 31 (5), 86-125.

Martix, S., \& Hodson, J. (2014). Teaching with infographics: practising new digital competencies and visual literacies. Journal of pedagogic development. 4(2), 17-27.

Meeusah, N., \& Tangkijviwat, U. (2013). Effect of data set and hue on a content understanding of infographic. AC, A2013 Thanyaburi: Blooming Color for Life Retrieved may 12, 2018, From http://www.repository.rmutt.ac.th/xmlui/handle/123456789/1263.

Mocek, E. (2012). Visual literacy and higher education's syllabus. Paper presented at the Society for Information Technology \& Teacher Education International Conference, 2012. (1), 2977-2982.

Nuhoğlu K., P., \& Akkoyunlu, B. (2017). Fostering and assessing infographic design for learning: the development of infographic design criteria. Journal of Visual Literacy, 36(1), 20-40.

Omar, A. M. (2016) Effectiveness of a Proposed Strategy Based on Infographic in the Acquisition of Scientific Concepts and the Development of Visual Thinking Skills and Enjoy the Learning of Science in the Fifth Grade Primary Pupils. Journal of Scientific Education, 19(4), 207- 268.

Ozdal, H., \& Ozdamli, F. (2017). The Effect of Infographics in Mobile Learning: Case Study in Primary School. J. UCS, 23(12), 1256-1275.

Ozdamli, F., \& Ozdal, H. (2018). Developing an instructional design for the design of infographics and the evaluation of infographic usage in teaching based on teacher and student opinions. EURASIA Journal of Mathematics, Science and Technology Education, 14(4), 1197-1219.

Ozturk, K. (2012). Presentation of Information in Press: Infographics and Illustrations. Masters' Thesis, Mustafa Kemal University, Social Sciences Institute, Hatay.

Parkinson, M. (2016). Infographic Tips and Tools. Talent Development,70 (5), 26-28.

Presmeg, N. (2014). Contemplating visualization as an epistemological learning tool in mathematics. ZDM, 46(1), 151-157.

Rezaei, N., \& Sayadian, S. (2015). The impact of infographics on Iranian EFL learners' grammar learning. Journal of Applied Linguistics and Language Research, 2(1), 78-85. 
Roehling, P. V., Kooi, T. L. V., Dykema, S., Quisenberry, B., \& Vandlen, C. (2010). Engaging the millennial generation in class discussions. College Teaching, 59(1), 1-6.

Saurbier, A. L. (2014). Using Infographies as an Integrative Higher-Order Skill Development Assignment in Undergraduate Leadership Instruction. Business Education Innovation Journal, 6(1) , 13-23..

Schrock, K. (2014). Infographics as A Creative Assessment. Retrieved September 29, 2014, from http://www.schrockguide.net/infographics-as-an-assessment.html.

Schroeder, R. (2004). Interactive Info Graphics in Europe--added value to online mass media: a preliminary survey. Journalism Studies, 5(4), 563-570.

Shafie, A. B., Janier, J. B., \& Ahmad, W. F. B. W. (2009, November). Visual Learning in Application of Integration. In International Visual Informatics Conference (pp. 832843). Springer, Berlin, Heidelberg.

Shafipoor, M., Sarayloo, R., \& Shafipoor, A. (2016). Infographic (information graphic); a tool for increasing the efficiency of teaching and learning processes. International Academic Journal of Innovative Research, 3(4), 39-45.

Singh, N., \& Jain, N. (2017). Effects of infographic designing on image processing ability and achievement motivation of dyscalculic students. In Proceedings of the International Conference for Young Researchers in Informatics, Mathematics and Engineering. Kaunas, Lithuania (Vol. 1852, pp. 45-53).

Smiciklas, M. (2012). The power of infographics: Using pictures to communicate and connect with your audiences. Que Publishing.

Sudakov, I., Bellsky, T., Usenyuk, S., \& Polyakova, V. (2014). Mathematics and climate infographics: A mechanism for interdisciplinary collaboration in the classroom. arXiv preprint arXiv:1405.6435.

Sukerti, G. N. A., \& Sitawati, A. A. R. (2019). Mastering Speaking Skill Through Project-Based Learning with Infographics: Perceptions and Challenges. September 14 15, 2019 Organized by Faculty of Letters, Universitas Negeri Malang (UM).

Toth, C. (2013). Revisiting a genre: Teaching infographics in business and professional communication courses. Business Communication Quarterly, 76(4), 446-457.

Vanichvasin, P. (2013). Enhancing the quality of learning through the use of infographics as visual communication tool and learning tool. In Proceedings ICQA 2013 international conference on QA culture: Cooperation or competition (p. 135).

Wertz, J., \& Saine, P. (2014). Using digital technology to complement close reading of complex texts. New England Reading Association Journal, 50(1), 78- 85

Yildirim, S. (2016). Infographics for Educational Purposes: Their Structure, Properties and Reader Approaches. Turkish Online Journal of Educational TechnologyTOJET, 15(3), 98-110.

Yıldıım, S., Yıldırım, G., Çelik, E., \& Aydin, M. (2014). Bilgi grafiği (infografik) oluşturma sürecine yönelik öğrenci görüşleri. Journal of Research in Education and Teaching, 3(24), 247-255. 